\title{
Emergency ward ultrasound: clinical audit on disinfection practices during routine and sterile examinations
}

\author{
A. Andolfo ${ }^{1 *}$, R. Maatoug ${ }^{2}$, N. Peiffer-Smadja ${ }^{3,4}$, C. Fayolle ${ }^{5}$ and K. Blanckaert ${ }^{6}$
}

\begin{abstract}
Context: In the emergency ward, where the use of ultrasound is common (including for sterile procedures), ward equipment is constantly exposed to high risks of microbiological contamination. There are no clear guidelines for disinfection control practices in emergency departments, and it is not known how emergency ward doctors follow good hygiene practices.
\end{abstract}

Method: A multi-centre audit was conducted in 16 emergency services from Northern France regional hospitals, in form of a questionnaire. It was proposed to all emergency ward physicians. We excluded questionnaires when physicians mentioned that they did not use ultrasound on a daily basis. The questionnaire was designed using existing hygiene and ultrasound disinfection practices guidelines from varying French medical societies. It included three different clinical scenarios: (a) ultrasound on healthy skin, (b) on injured skin, and (c) ultrasound-guided punctures. All questions were closed-ended, with only one answer corresponding to the guidelines. We then calculated compliance rates for each question, each clinical situation, and an overall compliance rate for all the questions.

Results: 104 questionnaires were collected, and 19 were excluded. For the 85 analysed questionnaires, the compliance rates were $60.4 \% 95 \% \mathrm{Cl}$ [56.4-64.7] for ultrasound on healthy skin, 70.9\% 95\% Cl [66.3-76.1] on injured skin and 69.4\% 95\% Cl [65.1-73.6] for ultrasound-guided punctures. The overall compliance rate for the compliance questions was $66.1 \% 95 \% \mathrm{Cl}$ [62.8-69.1]. Analysis of the questionnaires revealed severe asepsis errors, misuse of gel, ignorance of infection control practices to be applied in the context of ultrasound-guided puncture and exposure of the probe to body fluids.

Conclusion: This study details areas for quality improvement in the disinfection of emergency ultrasound scanner use. Consequently, we propose a standardized protocol based upon the recommendations used for the questionnaire drafting, with a visual focus on the low compliance points that have been revealed in this audit. This protocol has been distributed to all the medical emergency services audited and included in the emergency resident's ultrasound learning program.

Keywords: Ultrasound probes, Clinical audit, Disinfection, Reusable medical devices, Cross-transmission

*Correspondence: axlandolfo@gmail.com

${ }^{1}$ Service d'accueil des urgences/Structure mobile d'urgence et de reanimation, Centre Hospitalier de Dunkerque, 59140 Dunkirk, France

Full list of author information is available at the end of the article

\section{Introduction \\ Background}

Ultrasound systems are reusable medical devices that are increasingly used in the emergency ward. Over the last decade, scientific societies have given emergency physicians the possibility to practice and conduct more original author(s) and the source, provide a link to the Creative Commons licence, and indicate if changes were made. The images or other third party material in this article are included in the article's Creative Commons licence, unless indicated otherwise in a credit line to the material. If material is not included in the article's Creative Commons licence and your intended use is not permitted by statutory regulation or exceeds the permitted use, you will need to obtain permission directly from the copyright holder. To view a copy of this licence, visit http://creativecommons.org/licenses/by/4.0/. The Creative Commons Public Domain Dedication waiver (http://creativeco mmons.org/publicdomain/zero/1.0/) applies to the data made available in this article, unless otherwise stated in a credit line to the data. 
and more different types of examinations on their own, including invasive procedures [1].

The ultrasound probe is usually classified as a non-critical device by Spaulding's historical classification, and it only requires low level disinfection after patient contact [2].

However, when the ultrasound is used for an invasive procedure (e.g. inserting peripheral and central vein catheters, cavity puncture), there is a risk of contact with biological fluids, directly or through the sterile sheath. Moreover, various parts of the device, especially the probes, the keyboard and the gel vials are constantly exposed to bacterial contamination [3-5].

Good procedural practice recommendations for probe disinfection are currently available for semi-critical devices such as endocavitary ultrasound probes (EUP). The examinations carried out using these devices involve contacts with a mucous membrane, and sometimes an invasive sampling (e.g. prostate biopsies). General recommendations concerning good disinfection practices between two examinations were issued by the French Public Health institution in 2008, [6] and have been reinforced in 2016 [7], in a context of growing healthcareassociated infections.

These guidelines recommend performing a visual examination of the sheath itself and of the compress used to wipe the probe, to search for a potential blood or body fluid stain. If contamination of the probe is observed, an intermediate-level disinfection by soaking in a disinfectant solution is recommended. This sheath verification protocol is identical to the recommendations published by French anaesthesia and radiology societies. [8, 9].

Several recent assessments of professional practices (APP) have shown mediocre compliance rates with EUP hygiene measures: in France, one APP carried out with healthcare workers using EUP highlighted an ignorance of intermediate level disinfection procedures [10]. On a European scale, a survey of similar practices conducted by the European Radiological Society (ERS) describes the current level of compliance as worrying [11]. $11 \%$ of the surveyed radiologists did not use probe sheaths or covers for endocavitary examinations, and $23 \%$ of them did not do so during invasive procedures. Following this survey, the European recommendations were changed:

"The category 'semi-critical' as detailed in the Spaulding classification has been omitted. The generally accepted recommendations for disinfection are similar to those for critical procedures, i.e., transducers require high level disinfection or sterilization. [12]".

\section{Objectives}

The aforementioned APP were conducted on ultrasound professional practitioners, such as radiologists and gynaecologists, and not on emergency physicians. In France, there are no specific guidelines for ultrasoundguided invasive procedures. To date, neither hygiene practices of emergency ward doctors using ultrasound, nor their knowledge of existing ultrasound disinfection guidelines have been assessed. Their level of awareness of cross-contamination risks also remains to be determined, especially since emergency wards have a high potential for environmental contamination.

An audit was therefore conducted with the emergency services of our region. The objectives were to assess hygiene practices surrounding the use of the ultrasound system in the emergency department. We wanted to identify areas for improvement and propose a protocol for disinfecting ultrasound equipment based on actual hygiene guidelines.

\section{Methods \\ Study design}

The audit consisted in a declarative, anonymous, and multi-centre survey. It was conducted in all Hauts-deFrance region (Northern France) region hospitals that had an emergency department equipped with a functional ultrasound system. In total, 29 hospital centres (24 public hospitals and 5 private establishments) were contacted, and all emergency department chiefs were invited to take part in the study by phone call.

\section{Participants}

Once a hospital was included in the study, a survey coordinator was chosen among the medical team of each emergency department. There was no condition to become survey coordinator.

The survey link was sent to all survey coordinators, who were asked to relay it to all the practitioners who worked in their department. Practitioners included emergency physicians, other specialists that worked during daytime or nightshift in the emergency room, and current residents. Along with the link, a note detailed that the data would be used anonymously for a multi-centre survey and that practitioners were free not to participate. The note also emphasised the importance of answering honestly.

The entire questionnaire was completed online. The survey URL remained active for a period of 10 weeks, between September 14th and December 1st. At the end of October, a reminder was sent by email to every coordinator, to help maximise participation rates.

\section{Variables}

The different parts of the questionnaire were: 
- Q.2 The possibility for practitioners who did not use ultrasound in their daily routine to end the survey. Those practitioners were excluded from further analysis and the online questionnaire automatically ended.

- Q.1, Q.3 and "Age" Variables collected for bivariate analysis. (Q.1 from excluded questionnaires were not considered).

- Q.4-Q.13 Medical device cleaning resources and professional clothing.

- Q.14-Q.32 Guideline application in three clinical situations: (a) ultrasound on healthy skin, (b) on injured skin and (c) ultrasound-guided procedures. These were questions with correct answers and compliance rates. The third part [(c) ultrasound-guided procedures] was optional, to account for the fact that some participants were not used to such procedures. This part also included 4 questions on sheath verification protocol after an invasive procedure.

- Q.33-Q.35 Self-evaluation.

\section{Measurement}

Compliance questions related to gestures before, during and after an ultrasound examination: hand hygiene, probe wiping, keyboard wiping, correct use of sterile supplies like gel or covers, use of individual protection equipment and gloves, all in the right order. Every move is described in the guidelines, and many uncontrolled situations can lead to environment and/or patient contamination. To rigorously build this section of the questionnaire, we used the following sources:

1. Device disinfection recommendations [13], standard and contact precautions [14, 15], hand hygiene [16], all from the Société Française d'Hygiène Hospitalière (SF2H).

2. For ultrasound-guided procedures: EUP recommendations from the Haut Conseil de Santé Publique [7].

3 . For the sheath/cover checking protocol: recommendations from anaesthesiology [8], obstetric and radiology [9] societies.

Every question in this section was closed-ended, with one expected answer out of 2 or 3 propositions.

We determined compliance rates for each of the three clinical situations and a global compliance rate including all questions in this section, with confidence intervals. The questionnaire is fully available in Additional file 1.

\section{Bias}

Self-reports can be vulnerable to bias. However, given that the healthcare professionals surveyed in this study have received little information, evaluation, and lack clear guidelines on good ultrasound hygiene practices, we argue that their conscious need for such recommendations minimizes bias.

\section{Statistical methods}

Bivariate analysis: we compared every answer to our initial data:

- Age (<30 yo / 30-45 yo / > 45 yo).

- Trained or not in hospital hygiene (Q.1).

- Ultrasound diploma or not (Q.3).

To identify a potential link between behaviour and validated qualitative characteristics, we used Fisher's exact test (when the sample size permitted it). The significance threshold was $p<0.05$.

Missing data: Surveys whose compliance questions parts had five or more not answered questions were excluded from analysis.

Software used: 'SAS', version 9.4.

\section{Results}

Participants

Sixteen out of the 29 (55\%) hospitals in the Hauts-deFrance region (Northern France) accepted to participate in the study.

Only $8(50 \%, \mathrm{n}=16)$, declared that they had a protocol for ultrasound equipment disinfection.

104 questionnaires were completed and analysed. This represents $33 \%$ of all staff from the included emergency departments.

\section{Descriptive data}

Most of the participants $(87 \%, \mathrm{n}=104)$ were hospital or attending physicians in emergency medicine and $58 \%(60, \mathrm{n}=104)$ of them were between 30 and 45 years old. 81 were trained $(78 \%, \mathrm{n}=104)$ in hospital hygiene (local training by hygiene teams). 19 professionals (18\%, $\mathrm{n}=104$ ) declared that they did not use ultrasound in their daily practice and stopped the survey after Q.2. 85 participants declared that they did use ultrasound at various frequencies as described in Fig. 1. Among them, few emergency doctors were trained in using ultrasound, and only $14(17 \%, \mathrm{n}=85)$ had a university training in ultrasound techniques.

\section{Ultrasound use and disinfection}

93\% $(78, \mathrm{n}=84)$ of ultrasound practitioners used only gel bottle for daily routine ultrasound examination, and almost $80 \%(68, \mathrm{n}=84)$ did not bin the bottle $24 \mathrm{~h}$ after it had been opened. $41 \%(35, n=85)$ did not know if there 


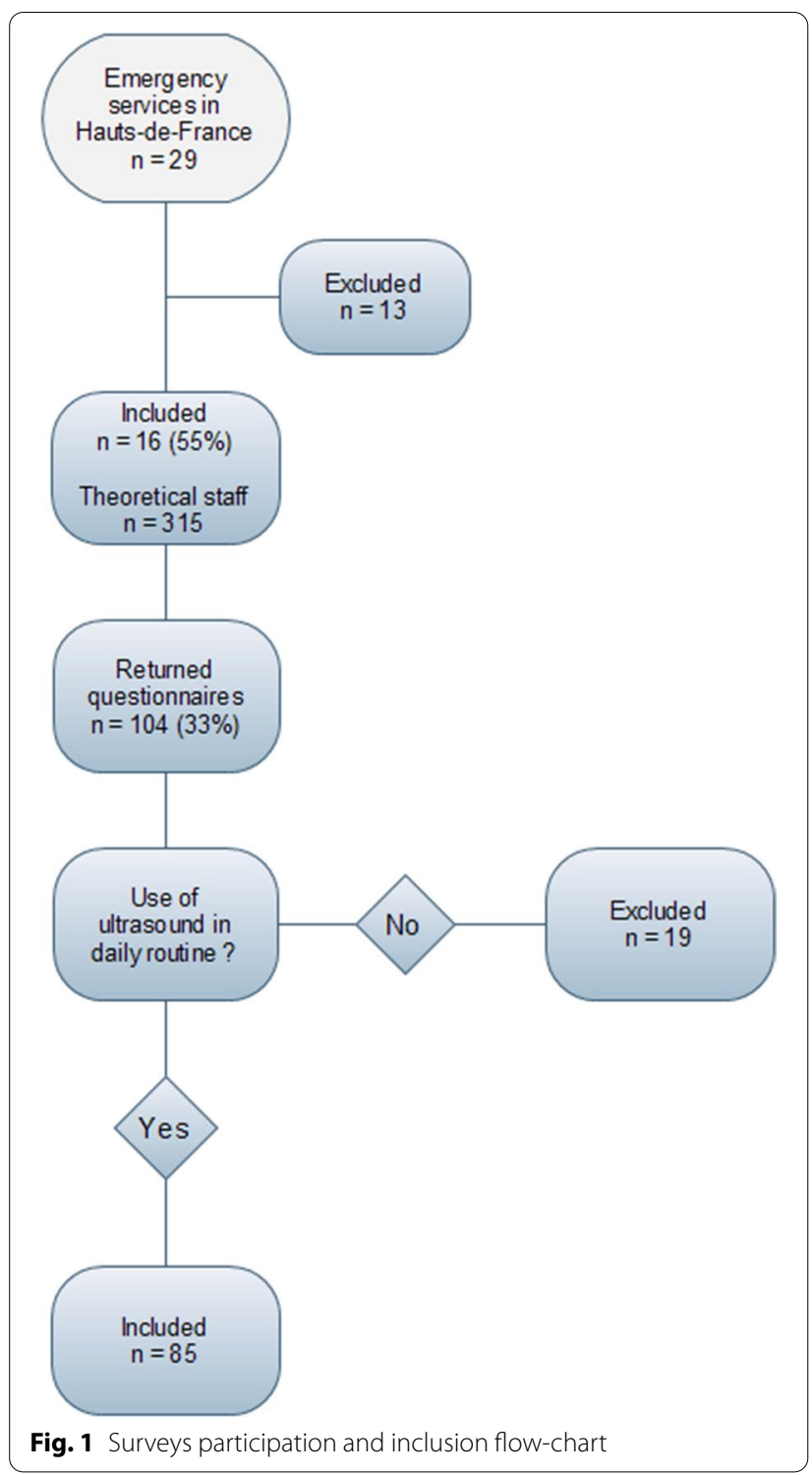

was a protocol for ultrasound system disinfection in their department.

\section{Compliance rates}

1. Per question A compliance rate of $100 \%(n=51)$ was observed only for one question (Q.23): the question concerning the use of sterile gloves for ultrasoundguided invasive procedures.

2. Per part and total The total compliance rate across the questionnaire was $66.1 \%$. Compliance rates for each part and the most significant non-compliance answers and confidence intervals are shown in Table 1.
3. Per participant None of the participants achieved an individual $100 \%$ compliance rate. Only 13 of them $(15 \% 95 \%$ CI [9.1-25.9], $\mathrm{n}=85)$ had a $100 \%$ compliance rate for one of the 3 parts. It was part b/ ultrasound examination on injured skin, for all of them.

4. Sheath checking procedure The compliance rates were very low regarding the verification of integrity of the sheath as described in Table 2.

5. The total missing data for Q.14 to Q.32 with $\mathrm{n}=85$, was 19 (1.2\% of all answers). None of the questionnaire had five or more missing answers in the compliance parts and none of them was excluded.

\section{Main results}

In summary, this study reveals several points to be improved by awareness-raising in the emergency services of the Hauts-de-France region:

- Probe disinfection before examination, especially for examinations on healthy skin, which are by far the most practiced on a daily basis.

- Treatment of environmental surfaces and of the various parts of the device after use, in particular the keyboard.

- Gel conditioning, the $250 \mathrm{~mL}$ bottle proving unsuitable because very often contaminated and too rarely renewed due to its frequent underuse, compared to obstetric or general imaging services.

- Contact protection equipment (sheath and nonsterile protection for single use) use and glove use for standard healthy skin procedure.

- Hygienic gestures to be adopted for a sterile procedure (hand hygiene by friction with hydroalcoholic solution, use of gel in sterile monodoses) and those to avoid (hand washing with antiseptic soap, use of non-sterile monodoses or use of gel from the bottle with sterile gloves).

\section{Bivariate analysis}

Bivariate analysis highlighted a statistically significant role of hospital hygiene training for 2 questions:

- The outfit used for ultrasound examination on injured skin (part (b)): only $26 \%$ of practitioners who were not trained in hygiene used a suitable gown or a disposable non-sterile protection, compared to $62 \%$ of those who were trained in hygiene. (Fig. 2, $\mathrm{n}=85$, $p<0.01)$

- Moreover, after an ultrasound-guided invasive procedure (part (c)), $90 \%$ of the professionals trained in 
Table 1 Compliance rates with $95 \%$ confidence intervals, and description of the most significant non-compliances with the guidelines

\begin{tabular}{|c|c|c|c|c|}
\hline (a) Ultrasound examination on healthy skin $(n=85)$ & Correct answer & n answered & n correct & $\%$ \\
\hline Probe disinfection before examination & YES & 85 & 32 & 38 \\
\hline Wearing gloves during examination & NO & 85 & 32 & 38 \\
\hline Keyboard disinfection after examination & YES & 85 & 16 & 19 \\
\hline \multicolumn{5}{|l|}{ Compliance rate part (a): 60.4\% 95\% Cl [56.4-64.7] } \\
\hline (b) Ultrasound examination on injured skin $(n=85)$ & Correct answer & n answered & n correct & $\%$ \\
\hline Use of a protective sterile sheath & YES & 84 & 35 & 39 \\
\hline Use of a disposable non-sterile protection & YES & 82 & 44 & 53 \\
\hline \multicolumn{5}{|l|}{ Compliance rate part (b): 70.9\% 95\% Cl [66.3-76.1] } \\
\hline (c) Ultrasound-guided invasive procedure ( $n=51$ : Optional part) & Correct answer & n answered & n correct & $\%$ \\
\hline Probe disinfection before procedure & YES & 51 & 30 & $59 \%$ \\
\hline Hand hygiene gesture executed before procedure & $\begin{array}{l}\text { Hand friction with hydroalco- } \\
\text { holic solution }\end{array}$ & 51 & 12 & $23 \%$ \\
\hline \multicolumn{5}{|l|}{$\begin{array}{l}\text { Other propositions: simple handwash with soap } 6 \%(n=3) \text {; Surgical scrub } \\
\quad 71 \%(n=36)\end{array}$} \\
\hline Type of gel container used & Sterile monodose & 50 & 42 & $84 \%$ \\
\hline \multicolumn{5}{|c|}{ Other propositions: Non sterile monodose 1\% $(n=1)$; Non sterile gel bottle 14\% $(n=7)$} \\
\hline Use of a protective sterile sheath & YES & 51 & 47 & $92 \%$ \\
\hline Keyboard disinfection after procedure & YES & 51 & 9 & $18 \%$ \\
\hline \multicolumn{5}{|l|}{ Compliance rate part (c): 69.4\% 95\% Cl [65.1-73.6] } \\
\hline Overall compliance rate (parts (a) (b) (c)): $66.1 \% 95 \%$ Cl [62.8-69.1] & & & & \\
\hline
\end{tabular}

Table 2 Compliance rates for sheath integrity after an ultrasound-guided invasive procedure

\begin{tabular}{|c|c|c|c|c|}
\hline Checking the integrity of the protective sheath $(n=51)$ & Correct answer & $\mathrm{n}$ answered & n correct & $\%$ \\
\hline \multicolumn{5}{|l|}{ By visually inspecting for: } \\
\hline A tear or a hole on the sheath & YES & 51 & 9 & 18 \\
\hline $\begin{array}{l}\text { Blood or body fluids contamination on the probe or on the dry paper used to remove gel } \\
\text { If one of these methods identifies a risk of probe contamination: }\end{array}$ & YES & 49 & 12 & 25 \\
\hline Existence of a specific disinfection procedure (intermediate level)? & YES & 51 & 5 & 10 \\
\hline Probe intermediate level of disinfection: Immersion in a disinfectant solution? & YES & 51 & 0 & 0 \\
\hline
\end{tabular}

Those compliance rates were not included in the overall compliance rates of the questionnaire shown in Table 1

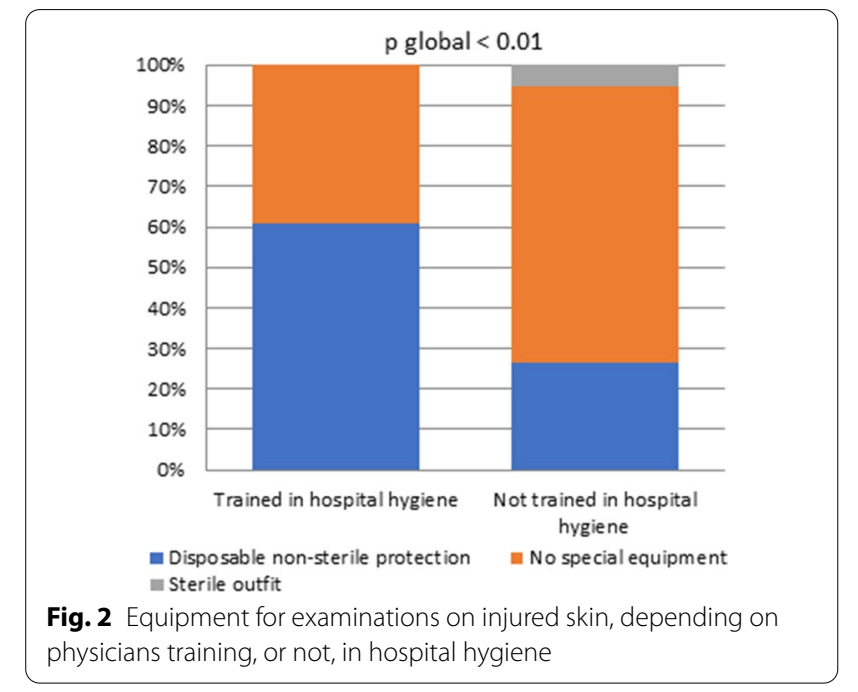

hospital hygiene perform a disinfection procedure (low disinfection level when no contamination has occurred) in contrast to $54 \%$ of untrained professionals (Fig. 3, $\mathrm{n}=85, p=0.01$ )

\section{Discussion}

\section{Key results}

The overall guideline compliance rate reported in this study is $66 \%$. It is acceptable, but insufficient. Some noncompliance areas carry higher cross-contamination risks than others.

For ultrasound on healthy skin, inadequate gloves use, reported in over $60 \%$ of professionals in this study, has already been highlighted in previous audits, and has been 


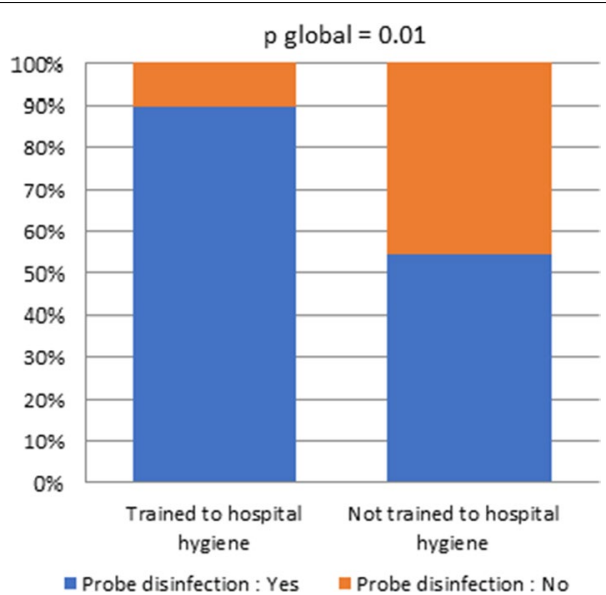

Fig. 3 Probe disinfection after ultrasound-guided invasive procedures depending on physicians training, or not, in hospital hygiene

shown to drastically impair hand hygiene [17]. Proper use of gloves thus plays a key role in adequate germ management.

For ultrasound on injured skin, although being the least common clinical situation in emergency departments, it was the only section of the survey for which some participants chose all the right answers (13 participants, so 15\% of surveyed professionals, $\mathrm{n}=85$ ). Nonetheless, almost half of the sample (47\%) reported not using personal protective equipment. $60 \%$ of them did not use the protective sheath, exposing the probe to a high risk of contact with biological fluids.

For ultrasound-guided procedures, non-compliance implies much greater risks: only one deviation from the guidelines can compromise the sterile environment. This represents a major risk if the needle used is no longer sterile at the time of puncture. Less than one out of 4 emergency doctors perform a hydro-alcoholic solution rubbing, as recommended in the guidelines. $71 \%$ of them still perform a surgical wash with iodine antiseptics, which is no longer indicated. Some emergency doctors also handle non-sterile products during the procedure: for example, $16 \%$ of them $(8, n=50)$, do not use a sterile gel container. Moreover, $6 \%$ of them $(3, n=51)$ do not use a cover at all, holding the probe with sterile gloves, and exposing it directly to body fluids. In this context, environment contamination (i.e. needle, patient, and probe) is thus unavoidable. These conclusions are in accordance with previous surveys in emergency professionals $[3,18]$.

For sheath integrity verification, our results are in line with European radiologists' worrying reports of noncompliance with the existing guidelines [11]. The same guidelines were used in this study, and it is clear that emergency physicians are unaware of this hygiene procedure. Besides, none of them appear familiar with intermediate-level disinfection by soaking, as none of them reported it.

\section{Limitations}

The form of the audit, namely a self-report, is limited due to its self-declarative nature. In addition, the questionnaire was relatively long and sometimes redundant. To reduce the potential social desirability bias, we choose to make the survey anonymous, and to not disclose that some questions were compliance questions. Indeed, this theoretically ensured that practitioners selected the behaviours they adopt themselves, instead of the ones they think they are supposed to adopt.

To further minimize this bias, we could have performed an observational audit. In fact, in addition to minimizing declaration bias, it could have allowed us to not provide detailed descriptions of the various gestures described in the guidelines. This could have enabled us to identify even more serious non-compliances, with stronger implications for patient safety.

However, we were dissuaded from proceeding this way because of the multicentric nature of the study and the impossibility of predicting routine examinations or invasive procedures for each emergency physicians willing to participate.

Another limitation of this study is that it does not offer targeted hygiene training based on its findings. The existing literature suggests that survey reminders of good practice have a significant positive impact on compliance rates [19]. Still, our bivariate analyses did not reveal enough statistically significant points to prove the benefit of hospital hygiene training, which is probably due to the low number of participants. Nonetheless, a feedback survey with detailed results and information on protocol implementation was sent to each survey coordinator.

Finally, the results were not analysed by centre due to very unequal participation rates from one centre to another. We cannot exclude a "centre effect", as no preliminary audit on ultrasound equipment maintenance protocols has been carried out prior to this investigation.

Regarding missing data, we have estimated that their very low number did not significantly change our conclusions.

\section{Interpretation}

The aim of this study was to determine whether emergency physicians who frequently perform ultrasound examinations are aware of the right practices to adopt in different clinical situations. The riskiest gestures, in sterile conditions, are not mastered by the participants of our study, and guideline non-compliance in routine 
examination situations also contributes to cross-transmission. However, in the latter, errors were less numerous and carried less risk. Still, misuse of the gel bottle, which is also an important contamination vector, carries significant risk. $93 \%$ of emergency doctors do not use a single dose of gel, and $80 \%$ of them never throw away a bottle that has been open for too long.

These findings are in line with published surveys of good practices to be observed during the repeated use of ultrasound [11]. Here, for the first time, we report similar issues in a largely understudied group of healthcare workers: emergency professionals.

Using the various recommendations from which we designed the questionnaire, we were able to highlight specific points of improvement. Consequently, we deemed it crucial to create a comprehensive protocol emphasising the most important and risk-carrying guideline non-compliances. In this protocol, the three different clinical situations studied are detailed. More specifically, for the ultrasound-guided puncture procedure, a particular emphasis is placed on the sterile nature of the material. Sheath verification after such examinations, as well as intermediate-level disinfection procedures are fully described and illustrated.

\section{Generalisability}

The results of our study cannot be generalised to all professionals using ultrasound in a hospital context. Indeed, we have chosen to study only the population of emergency physicians using ultrasound, thereby minimizing inclusion bias. Nonetheless, the multi-centric nature of this study, its high participation rate (over $50 \%$ of centres) and the very low number of excluded questionnaires $(18 \%, n=19)$ constitute several strengths for our study. As the survey was presented as an emergency ultrasound survey by the coordinators, it was probably of specific interest to practitioners who regularly use ultrasound. We therefore believe that the results are applicable to all emergency departments. More and more emergency physicians are indeed using ultrasound routinely, but often remain a minority in their departments.

Once the disinfection protocol (designed in a simple and illustrated way) had been validated by the local scientific authorities, it was printed in the form of a laminated sheet. We then distributed it to all emergency services in the region, including hospitals that had not participated in the survey.

Furthermore, it was integrated into the ultrasound course curriculum for emergency medicine students and circulated during the presentation on infectious risk management and hygiene of reusable medical devices. It is available on the CPIAS website [20] and an English version is attached in Additional file 2.

\section{Guidelines evolution}

In the US, the American College of Emergency Physicians has recently issued simple, concise and practical recommendations on the use and disinfection of ultrasound in the emergency ward [21]: if the level of semicritical risk still exists, disinfection at the intermediate level is no longer mentioned, dividing the disinfection procedures into high and low levels; echo-guided gestures falling into the latter category. The possibility of sheath injury with the needle is not considered. This is of primary importance for emergency ward doctors, and it partly motivated this audit.

Besides, in 2018, the American Institute of Ultrasound in Medicine recommended the use of a sterile sheath on the probe for all intracavitary examinations or interventional ultrasound-guided procedures. In case of needle damage, a high-level disinfection must be undertaken [22].

However, these changes are not directly applied by US practitioners. In fact, this study, conducted by the World Federation in Ultrasound for Medicine and Biology also highlights problems with sheath integrity verification protocol. The conclusion highlights the need for clear guidelines, as expressed by the majority of the thousand participants [23].

In France, changes in the workplace are slower. In fact, the intermediate-level disinfection procedure, eliminated by ACEP, has just been generalised and made compulsory between each patient for examinations using EUP, under the leadership of the SF2H and its president [24]. This is an intensification of practices that were previously recommended: a single intermediary disinfection per day at the end of the program.

The main obstacle to adaptations in routine ultrasound equipment uses in the emergency room remains probe immersion. It is not certain that the ultrasound scanners in emergency departments surveyed in this study are all compatible with disinfection by soaking in a disinfectant solution. In the future, we would thus wish to bring this matter to the attention of manufacturers. Another potential solution mentioned by SF2H is the use of more effective disinfectant wipes. In fact, SF2H reports that such wipes can eliminate naked viruses and prevent Human Papilloma virus contamination of the probes between obstetric endocavitary examinations.

\section{Conclusion}

Adoption of good hygiene practices during the repeated use of reusable medical devices can always be improved. Our study takes one example among many: the use of ultrasound by professionals working in emergency rooms. Echo-guided invasive procedures as well as simple ultrasound examinations can be performed routinely. 
Our work shows that aseptic and sterile environment conditions are rarely strictly respected.

In the absence of clear guidelines adapted to emergency departments and with increasing patient flows, cross contamination risks rise.

We propose a standardised protocol for ultrasound equipment disinfection based the main failures to comply with good practice recommendations revealed in our study. This protocol is ready to use and has been approved by the regional scientific authorities.

In the future, we could use an identical questionnaire or conduct an observational audit in order to define the impact of our protocol on ultrasound hygiene practices in emergency wards. It could also be useful to make more use of feedback and to provide short and local hygiene training courses for emergency department professionals.

Overall, French recommendations tend to be aligned with European and American guidelines. It is crucial to improve practitioners' awareness of and compliance with those guidelines, to reduce cross-transmission risks.

\section{Supplementary Information}

The online version contains supplementary material available at https://doi. org/10.1186/s13756-021-00896-w.

Additional file 1. Ultrasound disinfection practices protocol.

Additional file 2. Ultrasound equipment disinfection protocol.

\section{Abbreviations}

APP: Assessment of professional practices; CPIAS: Centre d'appui et de prévention des infections associées aux soins (Centre for support and prevention of healthcare-associated infections); ERS: European Radiology Society; EUP: Endocavitary ultrasound probe; SF2H: Société française d'hygiène hospitalière (French Society of Hospital Hygiene).

\section{Acknowledgements}

These guidelines were prepared and approved by the 'CPIAS Hauts-de-France', and do not necessarily reflect the opinions of Antimicrobial Resistance and Infection Control or its Editors

\section{Authors' contributions}

CF designed the work and did bibliography research. KB wrote the questionnaire, validated and published the protocol online. AA did bibliography research, collected the data in healthcare establishments, analysed them and wrote the article. RM did the statistical analysis and the English translation. NPS analysed the data and did a substantive revision of the work. All authors read and approved the final manuscript.

\section{Funding}

Not applicable.

\section{Availability of data and materials}

The data that support the findings of this study are available from the 'Réseau Santé Qualité Risques' of Hauts-de-France region, but restrictions apply to the availability of these data, which were used under license for the current study, and so are not publicly available. Data are however available from the authors upon reasonable request and with permission of the 'Réseau Santé Qualité Risques' (https://www.rsqr-hdf.com/).

Ethics approval and consent to participate Not applicable.
Consent for publication

Not applicable.

\section{Competing interests}

The authors declared that they have no competing interest.

\section{Author details}

1 Service d'accueil des urgences/Structure mobile d'urgence et de reanimation, Centre Hospitalier de Dunkerque, 59140 Dunkirk, France. ${ }^{2}$ AP-HP, Service de Psychiatrie Adulte de la Pitié-Salpêtrière, Institut du Cerveau, ICM, Sorbonne Université, 75013 Paris, France. ${ }^{3}$ French Institute for Medical Research (Inserm), Infection Antimicrobials Modelling Evolution (IAME), UMR 1137, University Paris Diderot, Paris, France. ${ }^{4}$ National Institute for Health Research Health Protection Research Unit in Healthcare. Associated Infections and Antimicrobial Resistance, Imperial College London, London, UK. ${ }^{5}$ Service de Réanimation et Unité de Soins Continus, Centre Hospitalier de Dunkerque, 59140 Dunkirk, France. ${ }^{6}$ Centre d'appui et de prevention des infections associees aux soins (CPIAS) Pays de la Loire, Centre Hospitalier Universitaire de Nantes, 44093 Nantes, France.

Received: 26 July 2020 Accepted: 21 January 2021

Published online: 30 January 2021

\section{References}

1. Second Level of Clinical Sonography in Emergency Medicine. French Society of Emergency Medicine (SFMU) guidelines by formal consensus. Ann Fr Med Urgence. 2018:8:193-202.

2. Spaulding $\mathrm{EH}$. Chemical disinfection and antisepsis in the hospital. J Hosp Res. 1957;9:5-31.

3. Shokoohi H, Armstrong P, Tansek R. Emergency department ultrasound probe infection control: challenges and solutions. Open Access Emerg Med. 2015;7:1-9. https://doi.org/10.2147/OAEM.S50360.

4. Oleszkowicz SC, Chittick P, et al. Infections associated with use of ultrasound transmission gel. Proposed guidelines to minimize risk. Infect Control Hosp Epidemiol. 2012;33:1235-7. https://doi.org/10.1086/66843 0 .

5. Devine J, Cooke RP, Wright EP. Is methicillin-resistant staphylococcus aureus (MRSA) contamination of ward-based computer terminals a surrogate marker for nosocomial MRSA transmission and handwashing compliance? J Hosp Infect. 2001;48:72-5. https://doi.org/10.1053/ jhin.2001.0955.

6. Avis du HCSP du 17 octobre 2008, relatif à la désinfection des sondes à échographie endocavitaire. 17p. (consultable on https://www.hcsp.fr/ explore.cgi/avisrapportsdomaine? clefr=45).

7. Ministère des affaires sociales et de la santé, Instruction $n^{\circ}$ DGS/VSS/ VSS1/DGOS/PF/PF2/2016/145 du 10 mai 2016 relative aux échographies endocavitaires, 3p. (consultable on http://www.hcsp.fr/explore.cgi/avisr apportsdomaine? clefr=561).

8. Société Française de Radiologie, Société d'Imagerie Ultrasonore, Recommandations d'hygiène lors des examens échographiques, Mars 2009, 4p.

9. Bouaziz H, et al. Société Française d'Anesthésie-Réanimation. Recommandations formalisées d'experts: Echographie en anesthésie locorégionale. Ann Fr Anesth Réanim. 2011;30(9):e33-5. https://doi.org/10.1016/j.annfa r.2011.06.008.

10. Réseau national de prévention des infections associées aux soins - Groupe d'évaluation des pratiques en hygiène hospitalière, 2016, Enquête relative aux pratiques d'hygiène appliquées aux sondes à échographie endovaginale, 61p. (consultable on: https://docplayer.fr/44872 307-Enquete-exploratoire-nationale-relative-aux-pratiques-d-hygie ne-appliquees-aux-sondes-a-echographie-endovaginale-resultats.html.

11. Nyhsen CM, Humphreys H, Nicolau C, Mostbeck G, Claudon M. Infection prevention and ultrasound probe decontamination practices in Europe: a survey of the European Society of Radiology. Insights Imaging. 2016;7(6):841-7. https://doi.org/10.1007/s13244-016-0528-z.

12. Nyhsen CM, Humphreys $H$, Koerner RJ, et al. Infection prevention and control in ultrasound-best practice recommendations from the European Society of Radiology Ultrasound Working Group. Insights Imaging. 2017;8(6):523-35. https://doi.org/10.1007/s13244-017-0580-3. 
13. Société Française d'Hygiène Hospitalière, Surveiller et prévenir les infections associées aux soins 2010, Consensus d'experts, 175p.

14. Société Française d'Hygiène Hospitalière, Précautions standard, recommandations 2018, 62p.

15. Société Française d'Hygiène Hospitalière, Prévention de la transmission croisée: Précautions complémentaires contact 2009, Consensus d'experts, 60p.

16. Société Française d'Hygiène Hospitalière, Hygiène des mains et soins: du choix du produit à son utilisation et à sa promotion, recommandations 2018, 92p. References [13-16] consultable on: http://www.cpias.fr/nosob ase/recommandations/sfhh/sfhh.html.

17. Girou E, Chai SHT, Oppein F, et al. Misuse of gloves: the foundation for poor compliance with hand hygiene and potential for microbial transmission? J Hosp Infect. 2004;57(2):162-9. https://doi.org/10.1016/j. jhin.2004.03.010.

18. Frazze BW, Fahimi J, Lambert L, Nagdev A. Emergency department ultrasonographic probe contamination and experimental model of probe disinfection. Ann Emerg Med. 2011;58(1):56-63. https://doi.org/10.1016/j. annemergmed.2010.12.015.

19. Messina G, Quercioli C, Burgassi S. How many bacteria live on the keyboard of your computer? Am J Infect Control. 2011;39(7):616-8. https:// doi.org/10.1016/j.ajic.2010.12.023.

20. American College of Emergency Physicans. Guideline for ultrasound transducer cleaning and disinfection. Ann Emerg Med. 2018;72:e45-7. https://doi.org/10.1016/j.annemergmed.2018.07.035.
21. American Institute of Ultrasound in Medicine. Guidelines for cleaning and preparing external- and internal-use ultrasound probes between patients \& safe handling and use of ultrasound coupling gel, 2018. www.aium. org/officialStatements/57. Accessed 20 Apr 2020.

22. Westerway SC, Basseal JM, Abramowicz JS. Medical ultrasound disinfection and hygiene practices: WFUMB global survey results. Ultrasound Med Biol. 2019;45(2):344-52. https://doi.org/10.1016/j.ultrasmedb io.2018.09.2019.

23. Société Française d'Hygiène Hospitalière, Proposition technique du groupe de travail national, Prévention du risque infectieux associé aux actes d'échographie endocavitaire, 2019, 28p. Consultable on https:// solidarites-sante.gouv.fr/IMG/pdf/fiches_sondes.pdf.

24. Centre d'appui pour la prévention des infections associées aux soin, Hauts-de-France, procédure de désinfection du matériel échographique selon les recommandations en vigueur, 2018. http://cpias.chru-lille.fr/ outilsEDS/Protocole\%20Echographie.pdf. Accessed 15 Mar 2019.

\section{Publisher's Note}

Springer Nature remains neutral with regard to jurisdictional claims in published maps and institutional affiliations.
Ready to submit your research? Choose BMC and benefit from:

- fast, convenient online submission

- thorough peer review by experienced researchers in your field

- rapid publication on acceptance

- support for research data, including large and complex data types

- gold Open Access which fosters wider collaboration and increased citations

- maximum visibility for your research: over 100M website views per year

At BMC, research is always in progress.

Learn more biomedcentral.com/submissions 